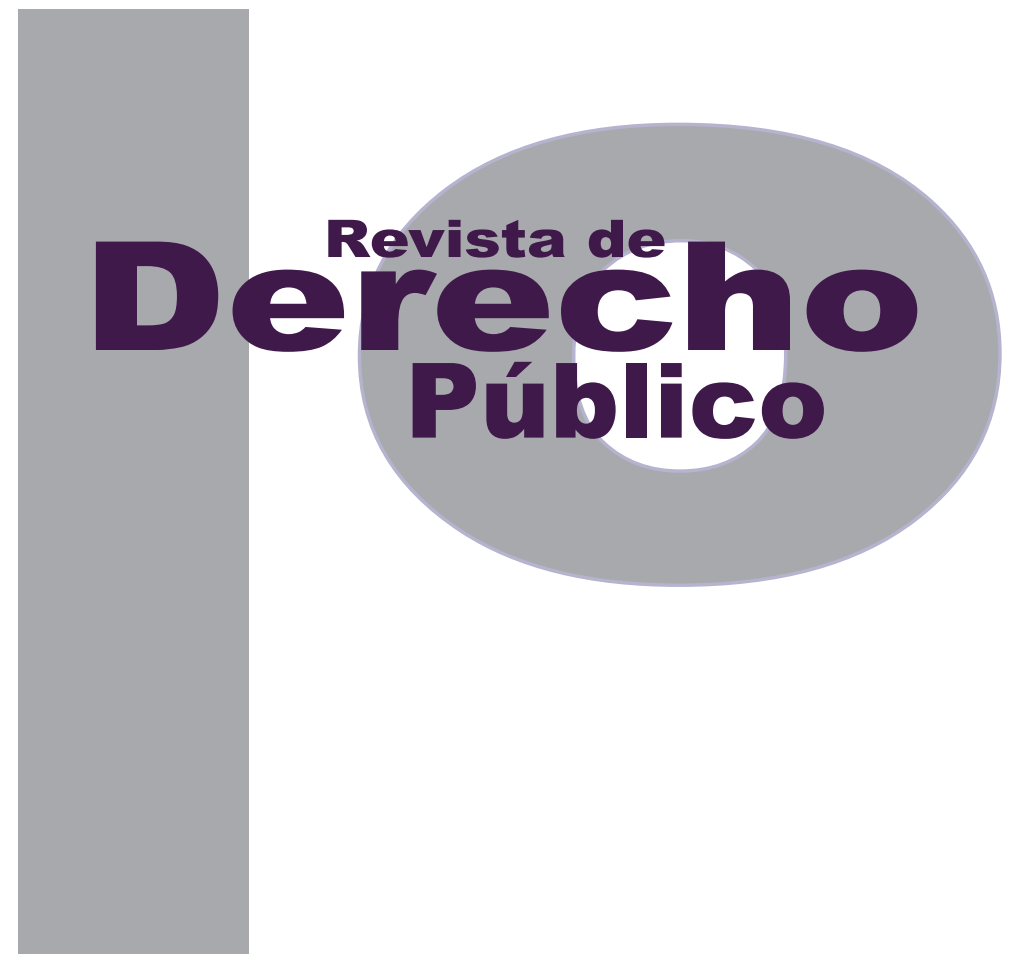

\title{
EL CONTROL DISCIPLINARIO DE LOS SERVIDORES PÚBLICOS ELEGIDOS POR VOTO POPULAR: UNA PROPUESTA DE REFORMA
}

\author{
Santiago Fajardo Peña
}

Artículo de reflexión

DOI: http://dx.doi.org/10.15425/redepub.34.2015.21

Universidad de los Andes

Facultad de Derecho

Revista de Derecho Público N. ${ }^{\circ} 34$

Enero - Junio de 2015. ISSN 1909-7778 


\section{El control disciplinario de los servidores públicos elegidos por voto popular: una propuesta de reforma}

\section{Resumen}

Con motivo de la destitución e imposición de una inhabilidad general para el ejercicio de funciones públicas al alcalde del Distrito Capital de Bogotá, el control disciplinario de los servidores públicos de elección popular se ha ubicado en el centro de las discusiones políticas y jurídicas del país. Esta reflexión busca presentar esta polémica a partir de la jurisprudencia nacional e internacional que se ha emitido sobre la materia, efectuar un análisis comparado de las experiencias de otros Estados suscriptores de la Convención Americana de Derechos Humanos y sugerir una alternativa de regulación que permita conciliar la necesidad de empoderar a jueces y autoridades de control para combatir la corrupción administrativa y proteger adecuadamente los derechos políticos.

Palabras clave: derecho disciplinario, Convención Americana de Derechos Humanos, derechos políticos, servidores públicos elegidos por voto popular.

\section{The disciplinary control of public officials elected by popular vote: a reform proposal}

\section{Abstract}

Due to the imposition of a general inability to exercise public functions to Mayor of the Capital District of Bogotá, the disciplinary control of public officials elected by popular vote is located in the center of the political and legal discussions of the country. The present document aims to present and analyze the disciplinary control of public officials elected by popular vote based on the national and international case law that has been issued on the matter. The considerations present hereby carry out a comparative analysis of the experiences in other Latin-American countries that have signed the American Convention of Human Rights in order to suggest an alternative to reconcile the claim to empower judges and control authorities to face government corruption and to give an adequate protection to political rights.

Key words: disciplinary law, American Convention of Human Rights, political rights, public officials elected by popular vote.

\section{O controle disciplinar dos servidores públicos elegidos por voto popular: uma proposta de reforma}

Resumo

Com motivo da destituição e imposição de uma inabilidade geral para o exercício de funções públicas ao prefeito do Distrito Capital de Bogotá, o controle disciplinar dos servidores públicos de eleição popular tem se localizado no centro das discussões políticas e jurídicas do país. Esta reflexão busca apresentar esta polêmica a partir da jurisprudência nacional e internacional que tem se emitido sobre a matéria, efetuar uma análise comparada das experiências de outros Estados subscritores da Convenção Americana de Direitos Humanos e sugerir uma alternativa de regulação que permita conciliar a necessidade de empoderar a juízes e autoridades de controle para combater a corrupção administrativa e proteger adequadamente os direitos políticos.

Palavras-chave: direito disciplinar, Convenção Americana de Direitos Humanos, direitos políticos, servidores públicos elegidos por voto popular. 


\title{
El control disciplinario de los servidores públicos elegidos por voto popular: una propuesta de reforma*
}

\author{
Santiago Fajardo Peña**
}

\section{SUMARIO}

Introducción - I. DESARROLLO DE LA REFLEXIÓN - II. FALLOS DISONANTES: PRECEDENTES NACIONALES E INTERAMERICANOS - A. Corte Interamericana de Derechos Humanos: el caso López Mendoza v. Venezuela - B. El voto concurrente del juez García Sayán: ¿una interpretación viva del artículo 23 de la CIDH? - C. La postura de las Cortes colombianas: un caso de desencuentro con la justicia interamericana - D. La sentencia fundadora de la línea: Corte Constitucional. Sentencia C-028 de 2006. M. P. Humberto Sierra Porto - E. La ruptura del consenso: Corte Constitucional. Sentencia SU-712 de 2013. M. P. Jorge Iván Palacio - F. La prolongación de la polémica: Corte Constitucional. Sentencia C-500 de 2014. M. P. Mauricio González Cuervo - G. El fallo de tutela del caso Petro: Consejo de Estado. Sala Plena de lo Contencioso Administrativo, rad. 06871 de 2014. M. P. Alfonso Vargas Rincón - H. Reacciones y críticas a la jurisprudencia local - III. ¿INSUMOS PARA UNA REFORMA? MODELOS DE CONTROL DISCIPLINARIO EN DERECHO COMPARADO - A. Pregunta para la investigación comparativa - B. Régimen disciplinario venezolano - C. Régimen disciplinario mexicano - D. Régimen disciplinario argentino - E. Análisis y conclusiones parciales del análisis comparado - IV. INSUMOS PARA UNA EVENTUAL REFORMA: LA INTRODUCCIÓN DEL PRINCIPIO ACUSATORIO EN MATERIA DISCIPLINARIA - A. EI principio acusatorio como elemento estructurador del régimen disciplinario de los SPEP - V. CONCLUSIÓN - Referencias.

\footnotetext{
* $\quad$ Cómo citar este artículo: Fajardo, S. (Junio, 2015). El control disciplinario de los servidores públicos elegidos por voto popular: una propuesta de reforma. Revista de Derecho Público, 34. Universidad de los Andes (Colombia).

** Abogado Summa Cum Laude de la Universidad de los Andes. Vinculado desde el año 2013 a la firma Holland \& Knight. Trabaja en las áreas de derecho tributario y derecho público. Correo: santiago.fajardo@hklaw.com

Agradezco los sugerentes comentarios y correcciones de los doctores Gustavo Quintero Navas y José Manuel Suárez.
} 


\section{Introducción}

La discusión alrededor de las facultades que ostenta el Ministerio Público (MP), ${ }^{1}$ en cabeza de la Procuraduría General de la Nación (PGN), en materia de investigación e imposición de sanciones disciplinarias sobre los servidores públicos designados por voto popular (SPEP) se ha puesto en el primer orden del debate jurídico y político del país. La necesidad de investigar y castigar los actos de corrupción y de encauzar el funcionamiento de la administración pública mediante la aplicación de sanciones disciplinarias ha entrado en tensión con la prevalencia de los derechos políticos de los SPEP. En este contexto, esta investigación responde la siguiente pregunta: teniendo en cuenta las obligaciones que ha contraído el Estado colombiano por la suscripción de la Convención Americana sobre Derechos Humanos ( $\mathrm{CADH})$, ¿de qué forma podrían reformarse las facultades atribuidas al MP en materia de control disciplinario sobre los SPEP

1 Aunque a lo largo del texto se alude indistintamente al Ministerio Público, y, en su cabeza, a la Procuraduría General de la Nación, debe subrayarse que esta última no es la única autoridad facultada para ejercer la acción disciplinaria. Según Isaza (2009), la potestad disciplinaria radica simultáneamente en la respectiva Oficina de Control Disciplinario Interno, en la Personería Municipal y en la Procuraduría General de la Nación; sin embargo, como quiera que las dos últimas entidades disponen de un poder disciplinario preferente y externo, ha de concluirse que el "juez natural disciplinario" de los servidores públicos es la Oficina de Control Disciplinario Interno de la respectiva entidad y que, excepcionalmente, dicha atribución la pueden ejercer la correspondiente Personería Municipal o la Procuraduría General de la Nación como partes o agentes del Ministerio Público. Ahora bien, ha de precisarse que las personerías (y con mayor razón la Procuraduría), son titulares del poder disciplinario preferente aun respecto de las entidades descentralizadas del orden municipal. Por el lado de los funcionarios judiciales, según lo preceptúa el artículo 256.3 de la Constitución Política, la Sala Jurisdiccional Disciplinaria del Consejo Superior de la Judicatura es la encargada de disciplinar a los funcionarios de la Rama Judicial del Poder Público. para adecuarla a los estándares ${ }^{2}$ internaciones de protección de derechos políticos?

Este escrito defiende la idea de que la obligatoriedad de la $\mathrm{CADH}$ en el ordenamiento colombiano, por virtud del bloque de constitucionalidad y del control de convencionalidad, debe dar lugar a un debate jurídico acerca de la conservación o eliminación de la facultad del MP de inhabilitar y destituir a los SPEP. Buscando plantear alternativas de regulación que puedan servir como fórmulas a tener en cuenta en una eventual reforma legal a esta institución, se sugiere derogar las normas de la Ley 734 de 2002 que facultan al MP para inhabilitar a los SPEP e introducir el principio acusatorio en materia disciplinaria para que sea un juez de lo contencioso administrativo el competente para suspender el ejercicio de derechos políticos de los SPEP, previa investigación y formulación de cargos del MP.

Una porción considerable de la literatura jurídica de derecho disciplinario ha estado dominada por lo que López (2007) denomina el "normativismo metodológico", que se caracteriza por dividir radicalmente los materiales jurídicos positivos de los diálogos sociales con lo que, en apariencia, se logra un mayor nivel de neutralidad en la aplicación de las normas, pero impide que estas sean interpretadas a partir de las metas o tensiones políticas que ellas traslucen. Bajo esta metodología jurídica tradicional, un buen

2 Siguiendo a Quinche (2009, pág. 32), se usa acá la expresión estándar como un criterio de evaluación del comportamiento de los Estados Partes del Pacto y como reglas jurídicas cuyo contenido implica el establecimiento de obligaciones concretas a los Estados, cuya inobservancia acarrea consecuencias en materia de responsabilidad internacional 
número de obras de derecho disciplinario (BuIla, 2009; Ramírez, 2008; Pineda, 2002) se caracteriza por empezar con las normas jurídicas:

Como puntos de partida y a veces también, y en ello radica su debilidad, como puntos de llegada pues se supone que ellas son capaces de "auto-explicarse" mediante interpretaciones textuales de las mismas y, en consecuencia, se escamotea el proceso de dar sentido a los procesos políticos, económicos y sociales en los que se crean e implementan las normas jurídicas (López, 2004, pág. 149).

Así, en este grupo de materiales, escritos a modo de manuales, predomina una forma descriptiva de redactar comentarios legales que siguen de manera cercana las divisiones en artículos, capítulos y libros del Código Disciplinario Único (CDU).

Este documento, que intenta separarse de esta orientación, acude al derecho comparado para problematizar el modelo de control disciplinario colombiano y para sugerir una salida a lo que puede considerarse como una incompatibilidad entre este y los estándares internacionales de protección de los derechos políticos.

\section{DESARROLLO DE LA REFLEXIÓN}

El escrito ha sido dividido en cuatro secciones. El capítulo II es descriptivo. En él se exponen los considerandos más importantes del fallo López Mendoza v. Venezuela. Así mismo, se presentan las sentencias proferidas por jueces locales sobre la validez de las facultades del mp frente al mandato del artículo 23.2 de la $\mathrm{CADH}^{3}{ }^{3}$ Esta sección también puede considerarse crítica debido a que registra algunos de los argumentos que se contraponen a la doctrina judicial establecida en el medio local. El capítulo III es comparativo en tanto que expone un estudio monográfico de los modelos de control disciplinario de México, Argentina y Venezuela con el propósito de identificar si alguno de estos países acometió o no procesos de reforma normativa para ajustar su diseño institucional a los estándares interamericanos de protección de los derechos políticos. Por último, el capítulo IV es propositivo por cuanto se apoya en el desarrollo del escrito para sugerir la adopción de una fórmula bajo la cual i) se superaría el debate en torno a la prevalencia de los poderes del mp por sobre los derechos políticos de los SPEP y ii) se conservarían, parcialmente, las funciones disciplinarias de la PGN.
3 El artículo 23 de la CADH señala textualmente: "1. Todos los ciudadanos deben gozar de los siguientes derechos y oportunidades: a) de participar en la dirección de los asuntos públicos, directamente o por medio de representantes libremente elegidos; b) de votar y ser elegidos en elecciones periódicas auténticas, realizadas por sufragio universal e igual y por voto secreto que garantice la libre expresión de la voluntad de los electores, y c) de tener acceso, en condiciones generales de igualdad, a las funciones públicas de su país. 2. La ley puede reglamentar el ejercicio de los derechos y oportunidades a que se refiere el inciso anterior, exclusivamente por razones de edad, nacionalidad, residencia, idioma, instrucción, capacidad civil o mental, o condena, por juez competente, en proceso penal". 


\section{FALLOS DISONANTES: PRECEDENTES NACIONALES E INTERAMERICANOS}

\section{A. Corte Interamericana de Derechos Humanos: el caso López Mendoza v. Venezuela}

Este fallo marca un punto de inflexión en el debate acerca de los límites a las potestades sancionadoras de la administración pública de cara a la protección de los derechos políticos en el Sistema Interamericano de Derechos Humanos.

Los hechos que fundamentaron este fallo de la Corte IDH, sucintamente, fueron los siguientes: el 4 de agosto de 2000, el señor Leopoldo López Mendoza, opositor político del entonces presidente Hugo Chávez, fue elegido por voto popular como alcalde del municipio de Chacao y reelegido en el mismo cargo el 31 de octubre de 2004. Al finalizar su mandato aspiraba a presentarse como candidato para la alcaldía del Estado Mayor de Caracas. Con todo, no pudo comparecer a dichos comicios pues había sido objeto de dos sanciones de inhabilidad que le fueron impuestas por el Contralor General de la República. Estas sanciones se impusieron en el marco de dos procesos administrativos.

El primero de ellos versó sobre hechos ocurridos mientras López se desempeñaba como analista en la Oficina del Economista Jefe de PDVSA, la empresa estatal de petróleos de Venezuela. Según señaló la Contraloría de dicho país, se habría configurado la responsabilidad de López por haber efectuado una donación en beneficio de la Asociación Civil Primero Justicia, siendo que él se desempeñaba, simultáneamente, como trabajador de PDVSA y como miembro de la Junta Directiva de la organización que recibió las donaciones.

El segundo de los procesos se desarrolló con motivo de una indebida gestión presupuestal de López cuando ocupaba el cargo de alcalde del municipio de Chacao. Según la ley presupuestal venezolana, a solicitud de los alcaldes, se autorizaba a declarar insubsistencias totales o parciales de ciertas partidas presupuestales no utilizadas en su totalidad o utilizadas parcialmente. A la altura del año 2002, el señor López Mendoza declaró la insubsistencia parcial de unos créditos presupuestarios y, junto con ello, el Concejo Municipal aprobó créditos adicionales financiados con los recursos provenientes de la mencionada partida. Según adujo la Contraloría de dicho país, se configuró responsabilidad administrativa pues si bien era una obligación del funcionario emplear los fondos del Estado, estos debían destinarse a las finalidades que le han sido encomendadas y no a objetivos diferentes, aunque estos últimos estuvieran relacionados con actividades inherentes a la propia administración.

Ante estos hechos, la Comisión Interamericana de Derechos Humanos (Comisión IDH) acusó al Estado venezolano de haber transgredido la Convención, pues la inhabilidad fue impuesta a través de un procedimiento administrativo y no por "condena, por juez competente, en proceso penal”. Este órgano sostuvo que en virtud de 
lo previsto en el artículo 23.2 de la Convención Americana, "es únicamente un tribunal judicial en un proceso penal el que puede restringir el derecho" y "cualquier restricción que se derive de dicho proceso deberá guardar estricto respeto a las garantías penales". Esto para concluir que la "Contraloría General y sus respectivas dependencias no son jueces o tribunales penales en sentido estricto y sus decisiones se suscriben al ámbito administrativo".

La Corte IDH formuló un silogismo deductivo para resolver este problema jurídico:

El artículo 23.2 de la Convención determina cuáles son las causales que permiten restringir los derechos reconocidos en el artículo 23.1, así como, en su caso, los requisitos que deben cumplirse para que proceda tal restricción. En el presente caso, que se refiere a una restricción impuesta por vía de sanción, debería tratarse de una "condena, por juez competente, en proceso penal". Ninguno de esos requisitos se ha cumplido, pues el órgano que impuso dichas sanciones no era un "juez competente", no hubo "condena" y las sanciones no se aplicaron como resultado de un "proceso penal", en el que tendrían que haberse respetado las garantías judiciales consagradas en el artículo 8 de la Convención Americana (párr. 107).

En resumen, además de constatar la responsabilidad internacional del Estado venezolano por la violación del deber de motivación, del derecho a la defensa en los procedimientos administrativos y de la protección judicial efectiva, la Corte IDH estableció una regla muy clara en torno a los límites de las potestades sancionadoras que afectan el ejercicio de derechos po- líticos: de conformidad con el numeral segundo del artículo 23 de la CADH, la inhabilidad para el ejercicio de funciones públicas que imposibilita el ejercicio del derecho político al sufragio pasivo, solo puede ser impuesta por una autoridad judicial en proceso penal. Cualquier hipótesis que no se ajuste a estas exigencias orgánicas estaría contraviniendo la CADH.

\section{B. El voto concurrente del juez García Sayán: ¿una interpretación viva del artículo 23 de la CADH?}

En esta reflexión no se acoge completamente la tesis sostenida por la mayoría de los jueces de la Corte IDH. En su lugar, se favorece, con base en el voto concurrente del juez Diego García Sayán al fallo López Mendoza vs. Venezuela, una interpretación menos rigorista del artículo 23.2 de la $\mathrm{CADH}$. Se parte de la base que, en términos orgánicos, sí debe ser un juez quien pueda suspender los derechos políticos mediante una inhabilidad, pero no solo un juez penal, sino cualquier autoridad jurisdiccional.

El problema jurídico que identificó el voto concurrente fue si el pluricitado artículo 23.2 excluye por completo la posibilidad de que se impongan limitaciones para ejercer cargos públicos por vías judiciales distintas a la penal o por vías administrativas, disciplinarias o a través de otros mecanismos. La respuesta que se le dio, y que se acoge plenamente en esta reflexión, indica que las limitaciones de los derechos políticos de naturaleza sancionatoria pueden ser adoptadas en otros espacios judiciales que también tienen legitimidad para actuar. Lo que es claro y fun- 
damental, indicó Sayán, es que cualquiera que sea el camino utilizado debe llevarse a cabo con pleno respeto de las garantías establecidas en la Convención y, además, ser proporcionales y previsibles. Esta es la hermenéutica más adecuada del artículo 23.2, pues una interpretación sistemática, evolutiva y teleológica, así como el análisis de los trabajos preparatorios de la CADH, apoyan dicha conclusión.

Una lectura sistemática del enunciado, como se señala en el voto concurrente, apunta a analizar esta norma de la Convención Americana en relación con otros instrumentos internacionales, universales y regionales de derechos humanos. Consultados estos tratados, se concluye que ni el Pacto Internacional de Derechos Civiles y Políticos, ni el Convenio Europeo de Derechos Humanos, ni la Carta Africana sobre Derechos Humanos y de los Pueblos prevén este tipo de limitaciones para restringir el ejercicio de derechos políticos, por lo que su justificación no es del todo clara en el plexo de instrumentos existentes en materia de protección de derechos humanos.

Por otro lado, con base en una interpretación historicista, se concluye que no se encuentra un importante debate ni sustentación acerca de los términos "exclusivamente por (...) condena, por juez competente, en proceso penal”. Este concepto, como se indica en el voto concurrente del juez García Sayán, fue incorporado solo en la última discusión del artículo sobre los derechos políticos, por una propuesta del delegado de Brasil. El delegado de Colombia y el miembro de la Comisión de Derechos Humanos presen- taron objeciones. Sin embargo, la enmienda fue aprobada y se hizo la inclusión en el texto definitivo del artículo. No consta, sin embargo, la razón o motivación por la que se presentó dicha enmienda ni se conoce del debate. Por ello, no es posible concluir con absoluta claridad cuál fue la intención de los Estados para la incorporación de dicho término en el actual artículo 23 de la Convención Americana.

Desde una perspectiva finalista se colige que la norma busca que los derechos políticos no queden al arbitrio o voluntad del gobernante de turno, con el fin de garantizar que la oposición política ejerza su posición sin restricciones indebidas y que el poder de persecución disciplinaria no sea instrumentalizado o aplicado con fines políticos. Por esta razón, las autoridades que gozan de autonomía e independencia funcional, como los jueces, serían los encargados de imponer la destitución del cargo y la inhabilidad para el desempeño de funciones públicas. Ello, si se tiene en cuenta que en estos casos no solo está en juego la afectación de los derechos de quienes se quieren postular sino los intereses colectivos de los electores. No es una situación, pues, igual a la de funcionarios designados, cualquiera que sea la vía de acceso (libre designación o concurso).

\section{La postura de las Cortes colombianas: un caso de desencuentro con la justicia interamericana}

Según lo señalado líneas atrás, las normas internas de los Estados que facultan a órganos de control fiscal o disciplinario, que no tienen 
naturaleza jurisdiccional para inhabilitar a funcionarios designados popularmente son incompatibles con lo dispuesto por la $\mathrm{CADH}$. En lo que concierne al caso colombiano, es necesario recordar que la PGN, en materia disciplinaria, sin perjuicio de ser uno de los órganos constitucionalmente autónomos, ejerce funciones administrativas, por lo que sus actos, auténticos actos administrativos de carácter sancionatorio, son pasibles de impugnarse ante la justicia contencioso administrativa para que revise su legalidad. Por este motivo deben tomarse con beneficio de inventario las locuciones "juez" disciplinario y "fallo" disciplinario, pues, como se anotó, en estricto sentido, se trata de una autoridad que cumple funciones administrativas y que emite actos administrativos, no providencias judiciales.

Habida cuenta de lo anterior, podría especularse con que la práctica de los tribunales domésticos al solucionar este problema jurídico consistió en anular las normas que confieren esta clase de poderes. Sin embargo, el caso colombiano exhibe una situación opuesta. Tanto la Corte Constitucional como el Consejo de Estado y el Consejo Superior de la Judicatura ${ }^{4}$ han ventilado criterios distintos.

Con esto en mente, en la siguiente sección se reconstruyen los razonamientos expuestos en cada una de las providencias. En la parte final

$4 \quad$ La sentencia de tutela emitida por el Consejo Superior de la Judicatura no se analiza puesto que, en lo que toca con el artículo 23 de la CADH, se limita a reproducir las consideraciones ventiladas en la sentencia SU712 de 2013. Véase: Consejo Superior de la Judicatura. Sala Jurisdiccional Disciplinaria. Sentencia de tutela de marzo de 2014. M. P. Pedro Alonso Sanabria Buitrago. Rad. n. ${ }^{\circ} 11001110200020130812001$. de este capítulo se hace una presentación analítica de los argumentos que se esgrimieron en los salvamentos de voto a la sentencia SU-712 de 2013 -que son extensibles al resto de fallos por su identidad temática y argumental-a efectos de evidenciar las críticas de las que son susceptibles estas decisiones.

\section{La sentencia fundadora de la línea: Corte Constitucional. Sentencia C-028 de 2006. M. P. Humberto Sierra Porto}

Aunque en varios pronunciamientos ${ }^{5}$ esta Corte había hecho referencia al control disciplinario de miembros de las corporaciones públicas, fue hasta este fallo en el que la Corporación abordó directamente el problema de la convencionalidad de la facultad de la PGN.

El problema jurídico que formuló la Corte fue si los artículos 44.1, 45, literal d) y 46, inciso 1 , de la Ley 734 de 2002, al consagrar como una de las posibles consecuencias del proceso disciplinario adelantado por la PGN la imposición de inhabilidades para el ejercicio de las funciones públicas, vulneraba el artículo 93 de la Constitución Política, en la medida en que, a su vez, contrariaba lo dispuesto por el artículo 23 de la $\mathrm{CADH}$, que establece que la ley puede reglamentar el ejercicio de los derechos políticos exclusivamente por razones de edad, nacionalidad, residencia, idioma, instrucción, capacidad civil o mental, o condena, por juez competente, en proceso penal.

$5 \quad$ Entre ellos las sentencias C-280 de 1996 y T-544 de 2004. 
La Corte desestimó el cargo planteado por el demandante con base en dos consideraciones que conforman la razón de la decisión del fallo. En primer lugar, señaló que una interpretación armónica de la $\mathrm{CADH}$ con otros instrumentos internacionales suscritos para la lucha contra la corrupción, como la Convención de las Naciones Unidas contra la Corrupción, que en su artículo 8.6 alude expresamente a la adopción de medidas disciplinarias, lleva a concluir que ese solo precepto no se opone a que los Estados adopten sanciones tales como la inhabilidad para el ejercicio de cargos públicos.

Con un sentido similar, para sustentar la constitucionalidad de las normas acusadas, la Corte Constitucional en la sentencia C-028/2006 planteó:

Es claro que el mencionado instrumento internacional forma parte del bloque de constitucionalidad y, por lo tanto, debe ser utilizado como parámetro que guíe el examen de constitucionalidad de las leyes colombianas, pero ello no significa que las normas pertenecientes al bloque adquieran el rango de normas supraconstitucionales. En ese sentido, la confrontación de una ley con un tratado internacional no puede dar lugar a una declaratoria automática de constitucionalidad o inconstitucionalidad, ya que es necesario, a su vez, interpretarla sistemáticamente con el texto de la Constitución (sentencia.

En síntesis, la Corte desestimó la existencia de normas de rango supra constitucional, y al considerar que distintos enunciados de la Carta como el artículo 277 autorizan al procurador a sancionar disciplinariamente a los SPEP, determi- nó que no era posible arribar a la declaratoria de inconstitucionalidad de la Ley 734 de 2002 cuando la misma Constitución confería el poder cuya validez se cuestionaba.

\section{E. La ruptura del consenso: Corte Constitucional. Sentencia SU-712 de 2013. M. P. Jorge Iván Palacio}

En esta ocasión, la Corte Constitucional efectuó un control concreto de constitucionalidad sobre una actuación disciplinaria en la que se declaró responsable a la entonces senadora Piedad Córdoba por haber incurrido "en las conductas consistentes en promover y colaborar con el grupo armado ilegal FARC-EP, constitutivas de la falta contenida en el numeral 12 del artículo 48 de la Ley 734 de 2002". Confirmado el acto administrativo de primera instancia por la PGN y verificada la comisión de una falta disciplinaria gravísima a título de dolo, la PGN sancionó a la congresista con destitución e inhabilidad general para ejercer cargos públicos.

Los cargos que se plantearon en la acción de tutela señalaban que: i) la PGN carecía de competencia para investigar y sancionar disciplinariamente a los miembros del Congreso y que ii) la viceprocuradora carecía de competencia para decidir la recusación formulada contra el procurador general de la Nación, de manera que este último no podía continuar conociendo de la investigación por encontrarse incurso en una causal de impedimento.

En primer término, la Corte señaló que en el ordenamiento jurídico colombiano la potestad 
disciplinaria del Estado en relación con los congresistas de la República no se agota con la acción de pérdida de investidura (control políticodisciplinario), ni con las medidas correccionales internas (control ético-disciplinario). De la mano de dichos procesos, indicó el Tribunal, los senadores y representantes a la Cámara pueden ser sujetos del control derivado del incumplimiento de sus deberes funcionales en su calidad de servidores públicos.

Según ese Tribunal, el artículo 118 que señala como una de las funciones del Ministerio Público la vigilancia de la conducta oficial de quienes desempeñan funciones públicas, el artículo 123 que prevé que los miembros de las corporaciones públicas entran en la categoría de servidores públicos y el numeral 6 del artículo 277 de la Carta que preceptúa que la PGN ostenta el poder de ejercer vigilancia superior de la conducta oficial de quienes desempeñen funciones públicas, inclusive las de elección popular, conforman una triada normativa que apoya la validez de dicha facultad.

Al lado de lo anterior, la Corte transcribió en extenso las consideraciones de la sentencia C-028 de 2006, presentada anteriormente. Con todo, la importancia de este fallo, al margen de la unificación del criterio de la Sala, consistió en que se examinó la aplicabilidad del fallo López Mendoza vs. Venezuela, sentencia que había sido emitida en el interregno comprendido entre la sentencia C-028 de 2006 y la emisión de este fallo de unificación.
La Corte arribó a la conclusión de que la regla de decisión de este precedente de la justicia interamericana no se ajustaba a las condiciones del caso bajo estudio. En primer lugar, atribuyó dicha inaplicabilidad al hecho de que:

[A diferencia de lo que prevé la Constitución de Colombia], de acuerdo con los artículos 42 y 65 de la Constitución de Venezuela: (i) el ejercicio de los derechos políticos solo puede ser suspendido por sentencia judicial firme en los casos que determine la ley, y (ii) no podrán optar a cargo alguno de elección popular quienes hayan sido condenados por delitos cometidos durante el ejercicio de sus funciones.

El Tribunal resaltó que en el proceso de responsabilidad fiscal surtido en contra del señor López Mendoza, a diferencia del caso que examinaba, también se había constatado la responsabilidad del Estado venezolano por la violación de los artículos 8.1 y 25.1 de la CADH, debido a la ineficacia de los recursos judiciales y la falta de motivación de los actos emitidos en el curso del procedimiento administrativo sancionatorio.

No debe dejar de mencionarse que la mayoría de la Sala, en un aserto algo paradójico, afirmó que "no desconoc[ía] que el control disciplinario de los Congresistas de la República por parte del Procurador General de la Nación puede presentar imperfecciones en un sistema ideal de frenos y contrapesos". 
F. La prolongación de la polémica: Corte Constitucional. Sentencia C-500 de 2014. M. P. Mauricio González Cuervo

En este, el más reciente pronunciamiento que sobre la materia ha emitido la Corte Constitucional, se estudió una demanda de inconstitucionalidad contra la expresión "inhabilidad”, contemplada en el ordinal 1 del artículo 44 de la Ley 734 de 2002 (Código Disciplinario Único). Entre los cargos que planteó el accionante se señaló que la competencia sancionatoria allí prevista desconocía los artículos 277.6 y 278.1 de la Constitución y los artículo 2, 23, 25 y 29 de la CADH. La infracción de tales normas convencionales implicaba, al mismo tiempo, la vulneración del artículo 93 de la Constitución Política. La Corte procedió a estudiar la falta frente a la totalidad del numeral 1 del artículo 44, que también contempla como pena por la comisión de faltas disciplinarias gravísimas la destitución del cargo.

Frente al primer argumento del demandante, que señalaba que este artículo del cDu contraviene el texto constitucional puesto que este no contempla la sanción de inhabilidad para el ejercicio de funciones públicas, la Corte Constitucional argumentó que sobre esta materia el legislador disciplinario goza de un amplio margen de configuración legislativa. Según el Tribunal, el hecho de que en tal disposición no se prevea la inhabilidad, no implica que el legislador esté impedido para fijarla, si se considera la libertad relativa de configuración que en esa materia se reconoce, entre otros, en los artículos 123, 124, 125, 150.23 y 293 de la Constitución (CConst., C-500/2014, M. González).
En lo atinente a la vulneración del artículo 93 de la Carta, por la también violación del artículo 23.2 de la $\mathrm{CADH}$, la Corte declaró estarse a lo resuelto en la sentencia C-028 de 2006, que había hecho tránsito a cosa juzgada constitucional, pues en esa providencia se habría evaluado con idénticos fundamentos normativos el cargo que indicaba que la Ley 734 de 2002 pugnaba con el estándar interamericano de protección a derechos políticos.

Los magistrados María Victoria Calle Correa, Alberto Rojas Ríos y Luis Ernesto Vargas Silva manifestaron su salvamento de voto respecto de la anterior decisión.

\section{G. El fallo de tutela del caso Petro: Consejo de Estado. Sala Plena de lo Contencioso Administrativo, rad. 06871 de 2014. M. P. Alfonso Vargas Rincón}

Aunque a la postre el proyecto de fallo que favorecía al alcalde Gustavo Petro fue derrotado, esta sentencia proferida por la Sala Plena de lo Contencioso Administrativo es interesante por cuanto aborda directamente el problema de la convencionalidad de la facultad del MP y además evidencia, como también sucedió en la Corte Constitucional, la disidencia de varios magistrados con la postura mayoritaria de la Sala. ${ }^{6}$

Resumidamente, el Consejo de Estado concluyó, actuando como juez de convencionalidad,

6 De cualquier modo, debe advertirse que la negación de la solicitud de amparo obedeció a que no se habrían reunido los requisitos necesarios para la procedencia de la tutela, esto es, la inexistencia de otros medios judiciales de defensa o la configuración de un perjuicio irremediable de conformidad con lo previsto en el Decreto Estatutario 2591 de 1991. 
que la facultad del mp es legítima por dos razones: en primer lugar, adujo la Sala Plena, "Ios precedentes constitucionales invocados por la parte demandada además de tener fuerza vinculante ofrecen una perspectiva que permite esclarecer el asunto competencial". Por otro lado, el Tribunal sostuvo que existe un margen de apreciación que la CADH otorga a los Estados miembros para el desarrollo y cumplimiento de sus disposiciones, que acompañado de la valoración de la arquitectura institucional del Estado colombiano en la Constitución en general y de la Procuraduría en particular, despeja cualquier duda que se tenga respecto de la competencia del ente de control para imponer esta clase de medidas.

En lo relativo a la aplicabilidad del caso López Mendoza vs. Venezuela, el Consejo de Estado insistió, en sintonía con la Corte Constitucional, que en él sí se había comprobado la violación de garantías procesales, razón por la cual no eran trasladables las consideraciones allí planteadas.

Nueve de los veintisiete magistrados de la Sala Plena de lo Contencioso Administrativo salvaron el voto. Argumentos tales como la procedencia de la tutela contra los fallos disciplinarios, la incompetencia de los operadores disciplinarios para hacer juicios de oportunidad y conveniencia sobre la aplicación de políticas públicas, hasta aseveraciones en torno a la configuración de un defecto fáctico por indebida valoración probatoria, así como la conducción ideologizada del proceso disciplinario, se plantearon en los distintos salvamentos. Sin embargo, el formulado por Jaime Orlando Santofimio, quien ha venido insistiendo en la penetración del control de convencionalidad en la actividad de los jueces administrativos, ${ }^{7}$ Ilama especialmente la atención. Según su decir, teniendo presente el reconocimiento de la Corte Constitucional en torno a las imperfecciones del actual diseño institucional en materia disciplinaria, el juez contencioso administrativo, en sede de tutela, estaba llamado a advertir que la disfuncionalidad institucional que se revela expone al Estado al incumplimiento de la CADH, en especial lo consagrado por el artículo 23.2. Por esto motivo, adujo Santofimio:

Si se procede a realizar un control objetivo de convencionalidad de lo consagrado en el artículo 277-6 de la Carta Política, puede resultar una seria contradicción que amerite la exhortación al Ejecutivo o al Legislativo, para se curse la iniciativa de enmienda constitucional, o legal, con el objetivo de adecuar y ajustar la mencionada disfuncionalidad que opera respecto al ejercicio y alcance de las competencias disciplinarias relacionadas con las sanciones de destitución e inhabilidad de servidores públicos de elección popular, en cabeza de la Procuraduría General de la Nación.

\section{H. Reacciones y críticas a la jurisprudencia local}

Frente a la doctrina judicial explicada párrafos atrás se han formulado una serie de argumen-

7 Este tratadista, actual magistrado de la Sección Tercera del Consejo de Estado, ha venido promoviendo la adopción de los estándares de reparación integral de la jurisprudencia interamericana en el contencioso de responsabilidad extracontractual. Al respecto puede consultarse: Brewer, A. y Santofimio, J. (2013). Control de convencionalidad y responsabilidad del Estado. Bogotá D. C.: Universidad Externado de Colombia. 
tos que buscan demostrar la incompetencia disciplinaria del MP sobre los SPEP.

\section{El texto constitucional no le reconoce al procurador, inequívocamente, la facultad de sancionar con destitución e inhabilidad a los congresistas}

Este señalamiento está contenido en el salvamento de voto de Luis Ernesto Vargas a la sentencia de unificación del año 2013 de la Corte Constitucional anteriormente presentada. Según la posición mayoritaria de la Corte, entre los enunciados constitucionales que estructuran la facultad de la PGN se encuentra el numeral 6 del artículo 277 de la Carta, que señala como funciones del procurador general las de "ejercer vigilancia superior de la conducta oficial de quienes desempeñen funciones públicas, inclusive las de elección popular; ejercer preferentemente el poder disciplinario; adelantar las investigaciones correspondientes, e imponer las respectivas sanciones conforme a la Ley".

Desde una interpretación textualista no se deduce inequívocamente, como parece entenderIo la Corte, la facultad del MP de sancionar a los SPEP. La proposición jurídica contemplada en este numeral estaría integrada por tres componentes normativos claramente distinguibles: el de la vigilancia de la conducta oficial, el del ejercicio preferente de la acción disciplinaria y el de la investigación e imposición de sanciones conforme a la ley. Ciertamente, el enunciado prevé que la función de vigilancia comprende a los funcionarios de elección popular, pero la norma no efectúa la misma aclaración en relación con el ejercicio del poder disciplinario preferente y la imposición de sanciones. Así las cosas, la norma habría delimitado la competencia constitucional en función de dos atribuciones distintas: la sanción y la vigilancia de los servidores públicos. Mientras resulta claro que la vigilancia sí se predica de los SPEP, no sucede lo mismo con la facultad sancionatoria. Esta incertidumbre semántica exigiría que se apelara a otros criterios hermenéuticos, pues la interpretación textualista de este enunciado no despeja las dudas en torno a la atribución de tal potestad. Para ello, sostuvo el magistrado Vargas, debería acudirse a una lectura integradora de otros principios constitucionales, particularmente, el principio democrático como dispositivo limitador de las potestades sancionadoras de la administración.

\section{El problema jurídico no debe ser estudiado desde el plano material sino desde el punto de vista orgánico}

En mi opinión, la posibilidad de que un SPEP sea objeto de una sanción como la destitución del cargo y la inhabilitación para el ejercicio de funciones públicas no constituye, en sí misma, la dificultad para armonizar el ordenamiento interno con el estándar interamericano de protección: el problema no es material o sustantivo, vale decir, no se predica de la función en sí misma, sino de quién la ejerce.

La Corte Constitucional y el Consejo de Estado suelen indicar que algunos instrumentos internacionales suscritos para la lucha contra la corrupción contemplan, como uno de los mecanismos para combatirla, las sanciones discipli- 
narias. Esta circunstancia, aducen ambas corporaciones, impediría ceñirse estrictamente a lo contemplado en el artículo 23.2, pues de lo contrario se configuraría una suerte de antinomia entre tratados debidamente ratificados por el Estado colombiano.

Para ser precisos, la CADH no se opone a que a nivel interno se adopten sanciones disciplinarias. Más bien, lo que ordena este instrumento es que cualquier medida restrictiva de los derechos políticos, como la inhabilidad y la destitución del cargo, sea fruto de una decisión judicial. El motivo para reservar dicha competencia a una autoridad jurisdiccional y sustraerla de la esfera de las funciones administrativas es que con ello se vigorizan las garantías de imparcialidad e independencia. En definitiva, el problema es orgánico, es decir, de cuál es la autoridad facultada, mas no sustantivo, esto es, de la facultad que se ejerce.

En este punto, el magistrado Luis Ernesto Vargas, en el salvamento citado, sostuvo:

Los pilares esenciales de la función jurisdiccional en un estado democrático de derecho son la independencia, la autonomía y la imparcialidad. Esos tres principios operan como garantía insustituible para todo aquel que deba enfrentarse o discutir un asunto ante la administración de justicia, y vienen a completar el complejo de garantías comprendido bajo el concepto de debido proceso. Ello explica que los procedimientos que pueden ocasionar interferencias particularmente graves en los derechos ciudadanos se atribuyan a autoridades judiciales.
El procedimiento disciplinario administrativo está cubierto por algunas de las garantías del debido proceso, las cuales podrían considerarse adecuadas para que quienes desempeñan funciones públicas ejerzan sus derechos a la defensa y contradicción, y sean sancionadas con base en reglas previamente definidas. Sin embargo, en el caso de los funcionarios electos por voto popular, la afectación es mucho más intensa, razón por la cual (según se explicará más adelante), el derecho internacional exige que sean adoptadas bajo reserva judicial.

\section{No es equiparable el grado de} protección que ofrece un procedimiento administrativo a un proceso judicial en relación con las garantías de las que son titulares los disciplinados

Tanto la Corte Constitucional como el Consejo de Estado han planteado que mientras se respete el debido proceso en las actuaciones disciplinarias la facultad del MP no colisiona con la $\mathrm{CADH}$. Con base en esta premisa, en la sentencia SU-712 de 2013 se dedujo la inaplicabilidad del fallo López Mendoza vs. Venezuela ya que en esa ocasión sí se habría demostrado la vulneración del derecho a un debido proceso.

En primer término, como resaltó el magistrado Vargas, este "razonamiento es superfluo, pues aunque en toda actuación administrativa se debe respetar el debido proceso, por expreso mandato constitucional, ello no iguala las garantías judiciales a las administrativas".

Y es que la distinción entre el debido proceso judicial y el administrativo, como señala Carva- 
jal (2010), no es artificiosa. La admisibilidad de mayores limitaciones al debido proceso en sede administrativa -piénsese en la consagración de tipos disciplinarios abiertos y en blanco-se afinca en los poderes exorbitantes de que dispone la administración y que hacen de ella un sujeto de derecho distinto a los demás.

Así, el derecho a un debido proceso podría sufrir mayores limitaciones cuando se trata de una autoridad administrativa que cuando se trata de la administración de justicia que, por definición, es independiente y neutral. Por ejemplo, en materia disciplinaria, el mismo funcionario que adelanta la indagación preliminar efectúa la apertura de la investigación, formula el pliego de cargos, celebra la audiencia de alegatos de conclusión, dicta el fallo de primera instancia, y un servidor perteneciente a su misma institución, como acontece en los expedientes sobre los que asume competencia la PGN, falla en segunda instancia.

Sobre este particular, vale la pena recordar el fundamento constitucional de la distinción entre acto administrativo y acto jurisdiccional en el marco del derecho administrativo sancionador. La Corte Constitucional, en sentencia C-189 de 1998, indicó:

No es incompatible con la autonomía de las funciones de control que sus actos sean calificados por la ley como administrativos, pues ello no confiere naturaleza administrativa a la actuación del órgano sino que simplemente señala que, debido a la ausencia de los requisitos de imparcialidad, independencia e inamovilidad de los funcionarios que los emiten, estos actos no son definitivos, pues pueden ser revisados por los jueces en cuestión. Por el contrario, si tales funcionarios reúnen las calidades propias de un juez, bien puede el ordenamiento conferirle efectos definitivos, esto es, jurisdiccionales a su decisión. Es más, la propia Carta y la jurisprudencia de la Corte muestran con claridad esa diferencia en materia de control disciplinario: así, las decisiones de la Procuraduría o de los superiores jerárquicos del investigado son administrativas, mientras que los fallos del Consejo Superior de la Judicatura son judiciales, y eso a pesar de que en todos los casos se trata del desarrollo de una función de control disciplinario.

\section{El fallo López vs. Venezuela, aplicable en estas controversias, sí exigía una cambio de línea jurisprudencial pues era un precedente con relevancia jurídica para el caso colombiano}

A efectos de demostrar que el citado caso sí debió originar un cambio de la línea jurisprudencial expuesta, debe evaluarse si se reunían o no los requisitos que se describieron en el reciente fallo C-500 de 2014 para que las autoridades judiciales internas apliquen las reglas de decisión de los órganos contenciosos del sistema interamericano. La Corte sostuvo que los pronunciamientos de la Corte IDH solo pueden obligar al Estado colombiano cuando este ha sido parte en el respectivo proceso. No obstante, señaló esa Corporación, podría considerarse hipotéticamente la posibilidad de reabrir un asunto previamente examinado por la Corte Constitucional, en aquellos casos en los cuales: (i) el parámetro de control haya sido una norma integrada al blo- 
que de constitucionalidad en sentido estricto; (ii) los pronunciamientos de la Corte IDH hayan variado radicalmente y de forma clara el sentido de la norma; (iii) la nueva interpretación resulte compatible con la Constitución Política; (iv) ofrezca un mayor grado de protección a los derechos, que el otorgado por la Constitución; (v) se integre a la ratio decidendi de las decisiones de la Corte IDH; y (vi) sea uniforme y reiterada.

Sin duda, el parámetro de control de constitucionalidad, esto es, el artículo 23.2 de la CADH, es un enunciado normativo que se integra al bloque de constitucionalidad en sentido estricto. Sumado a esto, en lo que toca con el segundo requisito para dar con la obligatoriedad del pronunciamiento sobre el caso López Mendoza, es claro que la interpretación que efectuó la Corte IDH entró en franca contradicción con el criterio que se expuso en la sentencia C-028 de 2006. La Corte IDH Sostuvo que los órganos que ejercen funciones administrativas no están facultados para establecer, en ejercicio de potestades sancionadoras, límites al disfrute de los derechos políticos. A su turno, la interpretación según la cual solo una autoridad jurisdiccional, no necesariamente penal, puede imponer a los SPEP sanciones tales como la inhabilidad y la destitución del cargo, resulta compatible con la Constitución Política pues como se procuró evidenciar en el punto inmediatamente anterior, en realidad, no hay contradicciones entre los preceptos constitucionales y convencionales. Finalmente, es claro que la razón de la decisión que declaró la responsabilidad jurídica internacional del Estado de Venezuela es la incompetencia de las autoridades administrativas para limitar el goce de derechos como el del sufragio pasivo.

Efectuadas esta serie de precisiones, debe concluirse que sí estaban dadas las condiciones para considerar la posibilidad de un cambio en la doctrina jurisprudencial. Según se lee en el salvamento de voto del magistrado Vargas a la sentencia SU-712 de 2013:

Desconocer el carácter de precedente de ese fallo y dirigirse abiertamente en contra de su sentido jurídico, se opone al cumplimiento de las obligaciones internacionales del Estado en materia de derechos humanos, y hace vulnerable la decisión adoptada en la sentencia SU-712/13 al escrutinio de los órganos competentes de derecho internacional. Solo una inconveniente vanidad judicial y no un compromiso inquebrantable con la vigencia de los derechos humanos, explica que la Corte Constitucional prefiera mantener una postura del año 2004 y hoy en día obsoleta, a asumir el cambio de orientación exigido por el principio democrático, el goce efectivo de los derechos políticos, y el actual conocimiento del derecho internacional sobre el alcance del artículo 23 de la Convención Americana sobre Derechos Humanos. 
5. Las especiales calidades que ostentan los SPEP permiten sostener que estos, en materia disciplinaria, deben gozar de un trato diferencial en relación con los trabajadores oficiales, empleados públicos y particulares que ejercen funciones administrativas

La tesis más extendida enseña que los artículos 118 y 123 de la Constitución colombiana serían las premisas que permiten inferir que los SPEP, al igual que los trabajadores oficiales y empleados públicos, son sujetos disciplinables y que, en tal condición, pueden ser objeto de sanciones como la destitución e inhabilidad para el desempeño de funciones públicas. Con todo, este análisis elude la integración del principio democrático entre los ingredientes normativos que deben incorporarse a la discusión.

Así lo señaló la magistrada Calle, quien indicó que:

Existen notorias diferencias entre los principios constitucionales que se afectan cuando se destituye a un servidor de elección popular, en la medida en que está cumpliendo un mandato electoral de carácter popular, y los principios comprometidos cuando se impone una destitución a un servidor nominado al margen de un certamen electoral y democrático. En el primer caso se afecta lo que la Corte ha denominado, en su jurisprudencia, el principio de representación efectiva, que es el mandato de conformar los cargos de elección popular con personas efectivamente electas, y no por otras nominadas. En el segundo caso, en cambio, tal consecuencia no se produce, pues la destitución de un funcionario nominado no implica una limitación del principio de representación efectiva, en la medida en que dicho servidor no es un representante electo en un certamen democrático.

Unos son los valores constitucionales que se ven comprometidos cuando se destituye e inhabilita a servidores públicos que están vinculados a las entidades públicas por una relación legal o reglamentaria o por una relación de carácter contractual laboral, y otros, bien distintos, los que se afectan cuando se impone mediante la inhabilitación una especie de interdicción política.

\section{III. ¿INSUMOS PARA UNA REFORMA? MODELOS DE CONTROL DISCIPLINARIO EN DERECHO COMPARADO}

Un estudio comparado de naturaleza funcionalista ${ }^{8}$ sobre los modelos de control disciplinario de los SPEP implementados por otros países suscriptores de la Convención es una importante herramienta para dar cuenta de algunas soluciones prácticas que podrían ser aplicadas a nivel interno para armonizar esta facultad con las previsiones de la CADH.

El objetivo de este acápite es doble. Desde el punto de vista descriptivo, pretende analizar cómo el modelo de control disciplinario sobre IOS SPEP, implementado por otros países suscriptores de la $\mathrm{CADH}$, ha logrado adaptarse a la

8 Decimos que el estudio está signado por el funcionalismo, en la medida que se apelará al principio de funcionalidad que "nos indica las áreas del sistema jurídico extranjero por estudiar a fin de dar con un equivalente o análogo de las soluciones presentes en el marco de un mercado de soluciones jurídicas" (Zweigert y Kötz, 2002, pág. 40). 
previsión contenida en el artículo 23 de dicha Convención. Desde el punto de vista prescriptivo, esta parte del trabajo pretende ofrecer soluciones prácticas que puedan implementarse en el orden interno, con miras a superar el debate ampliamente reseñado.

\section{A. PREGUNTA PARA LA INVESTIGACIÓN COMPARATIVA}

La pregunta de investigación que se busca responder en esta parte del escrito es la siguiente: ¿cómo los países suscriptores de la Convención Americana de Derechos Humanos han adaptado la parte orgánica de sus respectivas constituciones y, en particular, el diseño institucional del control disciplinario, frente al mandato contenido en el artículo 23.2 de la Convención, en cuya virtud, cualquier condena que limite o restrinja los derechos políticos del ciudadano debe provenir de una autoridad judicial?

Conviene hacer un par de comentarios. La pregunta de investigación se formuló con base en una hipótesis que indicaba que los países suscriptores de la CADH (también llamada Pacto de San José) sí ajustaron sus diseños institucionales para satisfacer el estándar de protección de los derechos políticos contenido en el artículo 23 de la mencionada Convención. En segundo lugar, debe advertirse que la referencia al "diseño institucional del control disciplinario" abarca cualquier forma o mecanismo institucional que pretenda controlar el correcto ejercicio de la administración pública, sin circunscribir este análisis a aquellos países en los que existe un órgano de control disciplinario independiente de las demás ramas del poder público. Más bien, el estudio se concentra en la posibilidad de imponer sanciones como la inhabilidad a los SPEP.

La metodología que se empleó en este acápite, como se dijo, es de cuño funcionalista toda vez que pretende analizar cómo el modelo de control disciplinario de diferentes países suscriptores de la $\mathrm{CADH}$ resuelve un problema análogo: la tensión que existe entre la necesidad de garantizar los derechos políticos de los SPEP, bajo los estándares del sistema interamericano, por un lado, y la necesidad de combatir la corrupción, por el otro. En el estudio del régimen disciplinario de cada país esta investigación no se restringe a las fuentes formales, sino que se ocupa también de la doctrina y la jurisprudencia.

Se renunció a escoger países con base en los conceptos de familia o tradición jurídica, por cuanto su rendimiento es bajo para los fines de la presente investigación. Los países seleccionados fueron: Venezuela, México y Argentina, todos ellos suscriptores de la CADH: México y Venezuela porque se caracterizan por un alto ${ }^{9} \mathrm{y}$ bajo ${ }^{10}$ grado de cumplimiento de la Convención, respectivamente; Argentina porque, además de

9 En México, el respeto y aplicación judicial de la CADH ha sido especialmente fuerte en razón de la amplia aceptación del control de convencionalidad, tanto así que la Suprema Corte de Justicia de dicho país, en la Resolución del 14 de julio de 2011 precisó que para las autoridades judiciales, administrativas y legislativas es obligatoria la aplicación oficiosa de la Convención.

10 El Estado de Venezuela ha sido renuente a la adecuación interna de su legislación, e incluso al acatamiento de las decisiones de los órganos interamericanos (Caso López vs. Venezuela), al punto que el expresidente Chávez lo retiró de la OEA y, en consecuencia, le arrebató la jurisdicción que los órganos del Sistema Interamericano tenían sobre este. 
ser uno de los máximos exponentes del derecho administrativo en Hispanoamérica, es un paradigma en la transición de la dictadura a la democracia, lo cual hace suponer que la tensión entre derechos políticos y corrupción es especialmente marcada. ${ }^{11}$

\section{B. Régimen disciplinario venezolano}

La Constitución venezolana le atribuye el ejercicio de la potestad disciplinaria a instituciones ubicadas en una rama independiente del poder público, denominada Poder Ciudadano. Sus artículos 273 a 291 consagran los entes que conforman dicho poder. El régimen disciplinario venezolano se caracteriza por ser un modelo de control externo, toda vez que la potestad disciplinaria recae sobre un organismo independiente de la administración, no adscrito a la Rama Judicial. Adicionalmente, el régimen disciplinario aplica a todos los funcionarios públicos, aun si fueren de elección popular.

El Estatuto de la Función Pública tipifica las conductas sancionables disciplinariamente. En él se enuncian también, de forma taxativa, las sanciones que, según la gravedad de la falta perpetrada, deben imponerse. Las sanciones van desde simples amonestaciones hasta des-

11 En 1994 la Constitución de la Nación Argentina de 1853 sufre una de las transformaciones más radicales e importantes de la historia constitucional de ese país. En dicha oportunidad se introdujo el catálogo de derechos fundamentales de la persona humana, evento que marca el tránsito constitucional hacia la democracia. Poco tiempo después, en 1997, por medio de la Ley 24759 del mismo año, Argentina adopta la Convención Interamericana contra la Corrupción, cuyo objetivo primordial era erradicar la corrupción, con miras a afianzar la democracia representativa. tituciones e inhabilidades temporales según lo contemplado en los artículos 82 y siguientes.

Desde el punto de vista orgánico, la Contraloría General de la República es la entidad encargada de investigar y fiscalizar los actos que pueden dar lugar a responsabilidad administrativa, así como aquellos en los que se ven comprometidos ilegítimamente el presupuesto y los recursos públicos. La Contraloría es una entidad independiente de la administración pública, no adscrita a la Rama Judicial del poder público.

En relación con el procedimiento disciplinario, existe una primera etapa de control y fiscalización interna ejercida por la respectiva entidad administrativa, seguida de un proceso público, de corte inquisitivo, ante los organismos del Poder Ciudadano, concretamente la Contraloría General de la República. Durante el curso del proceso disciplinario es posible solicitar la aplicación de medidas cautelares ante la jurisdicción de lo contencioso administrativa, a saber: a favor del procesado, la suspensión del acto administrativo sancionatorio, y en su contra, la detención provisional no mayor a seis meses. El procedimiento administrativo disciplinario, según Henríquez (2007), tiene los atributos de una actuación administrativa y, como tal, está sujeto a revisión jurisdiccional posterior en la especialidad de lo contencioso administrativo.

A modo de síntesis, conviene resaltar los elementos esenciales del derecho disciplinario venezolano: (i) la potestad disciplinaria se le atribuye a un órgano independiente de la administración, no adscrito a la Rama Judicial; (ii) 
el régimen disciplinario resulta aplicable a todo funcionario público, aun a aquellos de elección popular; y (iii) está prevista la sanción de inhabilitación apenas temporal, no permanente.

Así, pues, el modelo disciplinario venezolano estaría en contradicción con el estándar interamericano de derechos políticos, en la medida que un organismo no adscrito a la Rama Judicial está constitucionalmente autorizado para inhabilitar a los SPEP. La configuración normativa del régimen disciplinario no parece haber sido influenciada por el artículo 23 de la CADH. En efecto, no hay mención alguna en la exposición de motivos de la Ley Estatutaria de la Función Pública, alusiva a los estándares convencionales sobre protección de derechos políticos.

\section{Régimen disciplinario mexicano}

El régimen disciplinario de los servidores públicos en México ${ }^{12}$ se consagra, inicialmente, en el título IV de la Constitución Política de los Estados Unidos Mexicanos de 1917, que fue modificada en 1982. La Constitución, en su artículo 108 , dispone que son sujetos disciplinables los que hayan sido elegidos popularmente en el ámbito federal e incluye también a miembros de las entidades territoriales elegidos por voto popular, como los gobernadores de los estados, los diputados de legislaturas locales y los miembros de la Asamblea Legislativa del Distrito Federal. El numeral tercero del artículo 109 de la Constitución Federal dispone que los servidores

12 En el presente escrito, por razones de extensión, únicamente se analizará el régimen disciplinario común a todos los estados mexicanos, sin especificar las minucias de cada estado federado. públicos, además de la responsabilidad política, penal y civil en la que puedan incurrir por violaciones a la Constitución y la ley, también están sujetos a la responsabilidad administrativa derivada de actos $u$ omisiones que puedan afectar la legalidad, honradez, lealtad, imparcialidad y eficiencia de la administración pública.

El artículo 113 de la Constitución ordenó al Congreso de la Unión que expidiera las leyes necesarias para determinar las sanciones, los procedimientos aplicables y las autoridades competentes que debían regir el citado régimen disciplinario, facultándolo, entre otros, a que dichas sanciones consistieran en suspensión, destitución e incluso inhabilitación del servidor disciplinado. El Congreso procedió a expedir en 1982 la Ley de Responsabilidades de los Servidores Públicos, la cual contiene actualmente las normas, los procedimientos y las autoridades competentes que rigen la responsabilidad de los servidores públicos en temas de juicio político, declaración de procedencia y registro patrimonial de tales funcionarios.

Vale la pena destacar que hasta 2002 la citada norma contenía también las disposiciones relativas a la responsabilidad administrativa de los servidores públicos. Sin embargo, en noviembre del mismo año, el Congreso promulgó la Ley Federal de Responsabilidades Administrativas de los Servidores Públicos, a través de la cual se derogó el título I de la Ley Federal de Responsabilidades de los Servidores Públicos, quedando la primera de ellas como norma especial en los temas de responsabilidad administrativa. Esta norma contiene varios aspectos relativos a la 
responsabilidad administrativa. Inicia en su título II con los principios de la función pública (legalidad, honradez, lealtad, imparcialidad y eficiencia que rigen en el servicio público) y los sujetos de responsabilidad administrativa. Luego, su artículo 13, enlista las posibles sanciones a las que pueden verse sometidos los servidores públicos en caso de cometer faltas administrativas: amonestación privada o pública; suspensión del empleo, cargo o comisión por un período no menor de tres días ni mayor a un año; destitución del puesto; y sanción económica, e inhabilitación temporal para desempeñar empleos, cargos o comisiones en el servicio público.

Además de las sanciones, los distintos parágrafos del artículo 13 de la Ley de Responsabilidades Administrativas y el artículo 16 del mismo estatuto, contienen varios presupuestos importantes de destacar teniendo en cuenta el objeto de estudio de este escrito. Por un lado, el periodo de inhabilitación puede variar dependiendo de los daños o perjuicios causados y del beneficio económico obtenido por el servidor o el grado de la falta cometida (en el caso de infracciones graves también se debe destituir al funcionario). El término de la inhabilidad puede extenderse hasta los veinte años y el valor de las sanciones pecuniarias se tasa de acuerdo con el provecho obtenido.

Por otro lado, el artículo 16 de la citada ley prescribe los procedimientos necesarios para la imposición de las sanciones y las autoridades competentes para efectuarlos. Las autoridades administrativas como la Secretaría de la Función
Pública, las contralorías internas y las áreas de auditorías, quejas y responsabilidades, son las responsables de la imposición de las mencionadas sanciones. De acuerdo con ello, se destaca que el órgano responsable de proferir las decisiones administrativas sancionatorias es la Secretaría de la Función Pública. Según la Ley Orgánica de la Administración Pública Federal, esta dependencia del Poder Ejecutivo Federal no solo se encarga de vigilar que los servidores públicos federales se apeguen a la legalidad durante el ejercicio de sus funciones, sino que también coordina la labor de los órganos internos de control en cada dependencia del gobierno federal.

Vale la pena destacar que el artículo 25 de la Ley de Responsabilidades Administrativas permite que los servidores públicos que sean declarados responsables interpongan el recurso de revocación ${ }^{13}$ o impugnen directamente la resolución administrativa ante el Tribunal Federal de Justicia Fiscal y Administrativa, para que el juez especializado en materia contenciosa administrativa evalúe la legalidad de la decisión proferida.

Por lo anteriormente expuesto, es posible afirmar que en el caso mexicano, al igual que el colombiano, son instituciones no judiciales (administrativas ${ }^{14}$ ) las que tienen la competen-

13 Así lo contempla el artículo 25 de la Ley de Responsabilidades Administrativas cuando señala que las resoluciones que se dicten en el recurso de revocación serán también impugnables ante el Tribunal Federal de Justicia Fiscal y Administrativa.

14 En el caso mexicano, la Secretaría de la Función Pública es una institución perteneciente a la Rama Ejecutiva Federal. 
cia para destituir y sancionar con inhabilidad a servidores públicos, incluidos aquellos elegidos popularmente. Además, puede concluirse que la suscripción y ratificación de la CADH por parte de los Estados Unidos Mexicanos, en 1981, no alteró de ninguna forma el régimen disciplinario de esta nación puesto que, a pesar de que en años posteriores (2002) se efectuaron varias reformas a dicho régimen, estas no estuvieron influidas por los estándares interamericanos.

\section{Régimen disciplinario argentino}

El régimen disciplinario argentino encuentra su fundamento constitucional en los artículos 14 y 99 de la Constitución de 1853. El artículo 99 dispone que al Presidente de la Nación le corresponde remover los empleados cuyo nombramiento no estuviere regulado de otra forma por la Constitución. En esa medida, la potestad disciplinaria se le atribuye a la administración pública y no a un órgano independiente de ella. El artículo 14 consagra el principio de "estabilidad del empleado público". En virtud de este, los funcionarios públicos tienen derecho a no ser privados o separados del cargo sin justa causa. Se trata de un derecho fundamental en cabeza de todos los funcionarios públicos, toda vez que el ordenamiento jurídico argentino no distingue entre funcionario y empleado público. ${ }^{15}$ Como señala Marienhoff (1994, págs.

15 El artículo 3 del Decreto 41 de 1999 consagra que "los términos "funcionarios", "servidor", "agente", "oficial" o "empleado" se consideran sinónimos". Marienhoff (1994), no obstante, distingue entre funcionario y empleado público advirtiendo que "funcionario es el que actúa en jerarquía de cierto nivel superior; en tanto que empleado es el encuadrado en niveles jerárquicos de menor trascendencia con relación al funcionario" (pág. 42).
487-490), la Corte Suprema de Justicia argentina ha aclarado que, en virtud del artículo 14 de la Constitución, el ejercicio de la potestad disciplinaria no puede sustraerse del control judicial, toda vez que se trata de una actividad reglada y no discrecional.

Los funcionarios públicos, sin distinción alguna, deben observar una conducta acorde con la ética pública, so pena de ser sancionados o removidos de acuerdo con el régimen propio de su función, según lo prevé el artículo 3 de la Ley 25188 de 1999. En concreto, los funcionarios de la Administración Pública Nacional, centralizada o descentralizada, se sujetan al régimen disciplinario configurado por el Decreto 41 de 1999,16 la Ley 25164 de 1999 y el Decreto 1421 de 2002, con excepción de los ministros y secretarios, las máximas autoridades de organismos descentralizados, quienes ejerzan funciones de jerarquía equivalente y el personal militar. ${ }^{17}$ Especialmente quedan excluidos de este régimen los funcionarios de elección popular; lo cual implica que, pese a estar obligados a obrar de conformidad con la ética pública, no son sujetos disciplinables, en tanto el principio de taxatividad impera en materia disciplinaria. ${ }^{18}$

16 En su artículo 47 dispone que los funcionarios públicos de la Administración Pública Nacional están sujetos a las sanciones previstas en la Ley 22140 de 1980 (Régimen Jurídico Básico de la Función Pública), derogada por la Ley 25164 de 1999.

17 Al respecto, Marienhoff (1994) aclara que "la circunstancia de que determinados grupos de servidores del Estado estén expresamente excluidos del estatuto para el personal civil de la Administración Pública Nacional, no significa que (...) no sean "funcionarios o empleados públicos": solo significa que no están regidos por dicho estatuto" (pág 72).

18 Así se deduce de lo previsto en el artículo 3 de la Ley 25188 de 1999 y en el artículo 27 de la Ley 25164 de 1999. 
El régimen disciplinario dispone dos grupos de sanciones que aparecen específicamente enunciadas en el artículo 30 de la Ley 25164 de 1999. Las primeras se denominan correctivas y tienden a la enmienda del responsable. Dentro de ellas figuran el apercibimiento y la suspensión. Las segundas se denominan expulsivas o depurativas y tienden al alejamiento o exclusión del responsable. Dentro de ellas se encuentran la cesantía y la exoneración.

El apercibimiento no es sino un Ilamado de atención mediante el cual se le hacen saber al agente las consecuencias jurídicas que seguirán a la reiteración de los mismos hechos. (...) La suspensión, que no puede exceder de 30 días, consiste en la prohibición (...) de ejercer la función, con la correlativa privación de sueldo durante el lapso de suspensión (Marienhoff, 1994, pág. 423).

Finalmente, la cesantía y la exoneración son medios extintivos de la relación de empleo público. La cesantía comporta una sanción de menor gravedad que la exclusión. En consecuencia, mientras que la exoneración conlleva la baja en todos los cargos públicos ejercidos por el responsable, la cesantía supone el cese de funciones de un cargo específico. Ambas son sanciones de carácter transitorio porque el responsable podrá solicitar la rehabilitación para el ejercicio del cargo en dos o cuatro años, según se trate de cesantía o exoneración, respectivamente.

El régimen disciplinario no contempla como sanción la inhabilitación permanente para el ejercicio de cargos públicos. El Código Penal argen- tino, no obstante, prevé como pena accesoria de la pena de reclusión o prisión perpetua, la inhabilitación absoluta perpetua, aplicable a cualquier funcionario público, aun si fuere de elección popular. ${ }^{19}$ Pese a su nombre, la inhabilitación no es perpetua en realidad, puesto que el condenado puede ser restituido si durante diez años se hubiere comportado correctamente y hubiere reparado los daños ocasionados en la medida de lo posible.

El proceso disciplinario argentino es de índole acusatoria y se sujeta a las garantías del proceso penal, aunque en menor grado. Como garantía del debido proceso, la imposición de las sanciones de cesantía y exoneración exige la sustanciación de un sumario, que se sujeta a las reglas procesales contenidas en el Decreto 467 de 1999.

La Fiscalía de Investigaciones Administrativas, que forma parte del Ministerio Público Fiscal, funge como ente acusador para la iniciación de todo sumario. La Oficina Anticorrupción, creada en el ámbito del Ministerio de Justicia, Seguridad y Derechos Humanos, concurre con la Fiscalía de Investigaciones Administrativas como ente acusador, según lo dispone el Decreto 102 de 1999. La sustanciación del sumario le corresponde a la misma administración pública, en virtud del numeral 7 del artículo 99 de la Constitución. El funcionario competente para la sustanciación de los sumarios se denomina instructor. En concreto, la imposición de la san-

19 Así está consagrado en los artículos 5, 9, 12, 19 y 20 de la Ley 1179 de 1921, Código Penal argentino. 
ción de cesantía o exoneración corresponde a la autoridad superior con jerarquía no inferior a secretario de Estado o al titular de organismo descentralizado del que dependa el disciplinariamente responsable. Contra la decisión del instructor, que el artículo 122 de la Ley 24667 de 1996 denomina "resolución", procede el recurso administrativo que será resuelto por la Procuración General del Tesoro, que depende directamente del Presidente de la Nación. ${ }^{20}$

A modo de síntesis, el régimen disciplinario argentino se caracteriza por lo siguiente: (i) no aplica a funcionarios públicos de elección popular; (ii) la sanción de inhabilitación es temporal, del proceso penal aunque en menor grado. Los resultados de la investigación indican que el artículo 23 de la CADH no tuvo incidencia alguna en la configuración normativa del régimen disciplinario estudiado.

\section{E. Análisis y conclusiones parciales del análisis comparado}

Con el propósito de sistematizar los materiales estudiados, a continuación se presenta un cuadro en el que se incluyeron como variables una serie de conceptos lo suficientemente amplios para abarcar el heterogéneo conjunto de ordenamientos examinados.

\begin{tabular}{|c|c|c|c|c|}
\hline Variable & Colombia & Argentina & Venezuela & México \\
\hline Suscriptor de la Convención & $\mathrm{SI}$ & $\mathrm{SI}$ & $\mathrm{SI}$ & $\mathrm{SI}$ \\
\hline $\begin{array}{c}\text { Control disciplinario de funcionarios públi- } \\
\text { cos de elección popular }\end{array}$ & $\mathrm{SI}$ & $\mathrm{NO}$ & $\mathrm{SI}$ & $\mathrm{SI}$ \\
\hline Inhabilitación & $\mathrm{SI}$ & $\mathrm{SI}$ & $\mathrm{SI}$ & NO \\
\hline Inhabilitación permanente & $\mathrm{NO}^{21}$ & $\mathrm{NO}$ & $\mathrm{NO}$ & SI \\
\hline Órgano competente & Independiente & Administración & Independiente & Administración \\
\hline Control judicial & $\mathrm{SI}$ & SI & SI & Inquisitivo \\
\hline Sistema acusatorio/inquisitivo & Inquisitivo & Acusatorio & Inquisitivo & SI \\
\hline Garantías penales & SI & SI & SI & NO \\
\hline
\end{tabular}

no permanente; (iii) la potestad disciplinaria se le atribuye a la administración pública y no a un órgano independiente, pero está sujeta a control judicial; y (iv) el proceso disciplinario es de índole acusatorio y está dotado de las garantías

20 De conformidad con la Ley 24667 de 1996, el Procurador del Tesoro de la Nación depende directamente del Presidente de la Nación, tiene la jerarquía de un ministro y ejerce sus competencias con independencia técnica. Se trata, en esa medida, de un funcionario del Poder Ejecutivo Nacional.
21 Legalmente no hay previstas inhabilitaciones permanentes. Sin embargo, la Constitución de Colombia prevé en el inciso 4 del artículo 122 una inhabilidad atemporal para aquellos servidores que incurran en delitos que afecten el patrimonio del Estado o cuya conducta dolosa o gravemente culposa, así calificada por sentencia judicial ejecutoriada, lleve a que el Estado sea condenado a una reparación patrimonial. Como se notará, esta opera de pleno derecho, por mandato constitucional y no es impuesta por la pgn, sino que requiere una condena penat.

22 Debe ponerse de presente que de conformidad con el artículo 25 del Código Penal venezolano "la inhabilitación para el ejercicio de alguna profesión, industria o arte no puede ser perpetua ni absoluta, sino temporal y limitada a determinada o determinadas profesiones, industrias o artes." 
Nota: todas las variables toman por valor sí o No, con excepción de las variables "órgano competente" y "sistema acusatorio/inquisitivo". La primera puede tomar por valor "administración", “judicial” o “independiente”, según que la potestad disciplinaria sea ejercida directamente por la administración, por la jurisdicción o por un órgano independiente de ambas. La segunda puede tomar por valor "acusatorio" o "inquisitivo", según los rasgos del proceso disciplinario.

La hipótesis con base en la cual se formuló la pregunta de investigación de esta sección resultó falseada. Por lo menos para la muestra de casos estudiada se concluye que, en realidad, no ha operado una adaptación de la parte orgánica de sus respectivas constituciones y, en particular, del diseño institucional del control disciplinario, frente al mandato contenido en el artículo 23.2 de la CADH. Si bien en el caso argentino los SPEP no son sujetos pasivos de inhabilidades que sean impuestas en el marco de un procedimiento administrativo sancionador, este hecho obedece a las particularidades del régimen constitucional y legal del país, no así al cumplimiento del compromiso internacional de protección de derechos políticos. En definitiva, el estándar de protección de derechos políticos y la jurisprudencia interamericana en la materia no han animado ningún proceso de reforma legal o constitucional.

Aunque en este componente del trabajo no se buscaba rastrear las razones por las cuales ninguno de los países suscriptores ha acometido procesos de reforma constitucional o legal en materia de potestades sancionadoras de la ad- ministración para privilegiar el ejercicio de derechos políticos, pueden formularse, de manera preliminar y como objeto de un posterior estudio, las siguientes hipótesis:

El fallo López Mendoza vs. Venezuela es muy reciente. Si bien este precedente ha aclimatado el debate en países como Colombia, al ser más rígidos procedimentalmente y más costosos en términos políticos por recortar facultades confeccionadas para combatir el fenómeno de la corrupción, estos procesos de reforma constitucional o legal pueden presentarse en años venideros.

Los Estados Parte de la Convención, a pesar de obligarse a satisfacer los estándares previstos en materia de derechos políticos mediante la adecuación de sus legislaciones internas, no fueron conscientes de las implicaciones que conlleva disponer que solo un juez, en proceso penal, pueda restringir el ejercicio de los derechos políticos. Esto se evidenciaría con la ausencia de un debate sesudo en los antecedentes y recomendaciones en la elaboración de la CADH.

\section{INSUMOS PARA UNA EVENTUAL REFORMA: LA INTRODUCCIÓN DEL PRINCIPIO ACUSATORIO EN MATERIA DISCIPLINARIA}

En el plano estrictamente jurídico, en este estudio se cree haber demostrado que la controversia está lejos de ser zanjada: la disparidad de criterios entre tribunales locales e internacionales, sumada al gradual crecimiento de los salvamentos de voto en los fallos que han 
abordado el problema jurídico de la convencionalidad de las facultades del MP pone de relieve esta circunstancia.

Como una contribución para este debate, a continuación se pretende demostrar las bondades que reúne una posible alternativa: la introducción del principio acusatorio en materia disciplinaria.

\section{A. El principio acusatorio como elemento estructurador del régimen disciplinario de los SPEP}

El principio acusatorio puede ser identificado como una de las máximas organizativas de los procedimientos judiciales y administrativos. La función organizativa del principio acusatorio radica en que este permite determinar bajo qué distribución de roles y bajo qué condiciones se efectuará el enjuiciamiento de la pretensión, sin que esta, necesariamente, sea de naturaleza penal.

La identificación teórica de los rasgos esenciales de este principio no es sencilla. Con todo, siguiendo a Ferrajoli (2009, pág. 564), puede llamarse acusatorio a todo sistema procesal que concibe al juez, en nuestro caso al operador disciplinario, como un sujeto pasivo rígidamente separado de las partes, y al juicio como una contienda entre iguales iniciada por la acusación, a la que compete la carga de la prueba, enfrentada a la defensa en un juicio público, contradictorio, oral, con inmediación probatoria y resuelto a través de la libre convicción de los medios de conocimiento.

Si hay un rasgo de la esencia de los esquemas organizativos acusatorios es la separación en- tre instrucción y juzgamiento. El principio exige invariablemente el desdoblamiento de las funciones de acusación y de decisión o, lo que es lo mismo, el cumplimiento del aforismo nemo iudex sine acusatore. La garantía de separación, así entendida, representa, por una parte, una condición esencial de la imparcialidad del juez respecto de las partes de la causa; por otra, es un presupuesto de la carga de la imputación disciplinaria y de la prueba, que pesan sobre la acusación o formulación de cargos. Esta separación del juez de la acusación, indica Ferrajoli (2009), supone la configuración del proceso como una relación triangular entre tres sujetos, dos de los cuales están como partes, y el tercero como supra parte.

Presentada sucintamente la filosofía que anima el principio acusatorio, a continuación se plantea brevemente el modo en que podría quedar configurado un proceso disciplinario judicializado de naturaleza acusatoria. La cuerda procesal de este sistema seguiría más o menos de cerca la estructura consagrada en el CDU, introduciendo el gran cambio que representa desplazar la competencia del juzgamiento disciplinario. ${ }^{23}$

El MP conservaría, parcialmente, las competencias disciplinarias con las que actualmente cuenta frente a los SPEP. Esta entidad se encargaría de llevar a cabo la indagación preliminar y de dar apertura a la investigación disciplinaria si

23 Es necesario reconocer que esta idea ya había sido concebida por el profesor Gómez Pavajeau (2009) quien, a pesar de haberla presentado en otro contexto, delineó los principales ajustes que demandaría un proceso disciplinario acusatorio. 
encuentra mérito probatorio en las averiguaciones preliminares.

Tal y como se contempla en el artículo 161 del CDU, cuando se haya recaudado prueba que permita la formulación de cargos, o vencido el término de la investigación, el funcionario encargado de la instrucción, mediante decisión motivada, evaluaría el mérito de las pruebas recaudadas y formularía pliego de cargos contra el investigado. En caso contrario, ordenaría el archivo de la actuación.

Formulado el pliego de cargos se trabaría la relación jurídica procesal y asumiría competencia el juez de conocimiento, un juez contencioso administrativo. Los sujetos procesales o partes serían, el acusador disciplinario, el mp y el sujeto investigado: el SPEP.

A decir verdad, con este tipo de proceso se conservarían plenamente la enunciación de faltas disciplinarias, deberes y prohibiciones para estos servidores públicos, e incluso, se mantendrían, para efectos sancionatorios, las penas de inhabilidad general y destitución, con la única variación de que tal determinación sería fruto de una decisión judicial.

La competencia de las autoridades judiciales, en primera instancia, la asumirían los tribunales administrativos, y la apelación de los fallos proferidos por estos podría ser de competencia de la sección segunda o quinta de la Sala de lo Contencioso Administrativo del Consejo de Estado. ${ }^{24}$

24 No es caprichosa la alusión a la sección segunda y quinta de la Sala de lo Contencioso Administrativo del Consejo de Estado como los po-
En este procedimiento tendrían plena aplicación todas las garantías de orden sustantivo y procesal, consagradas constitucional y legalmente. Los principios del debido proceso, legalidad, favorabilidad, presunción de inocencia, igualdad ante la ley, reconocimiento de la dignidad humana, resolución de la duda en favor del disciplinado, entre otros, se conservarían como los principios rectores del proceso disciplinario acusatorio.

Se trata de una presentación aún muy precaria de cómo podría ser estructurado un sistema procesal disciplinario de corte acusatorio para IOS SPEP. Y si bien este modelo también podría extenderse a toda clase de servidores públicos, como ya se expresó, las especiales calidades que revisten los SPEP serían un motivo constitucionalmente válido y suficiente para justificar su tratamiento diferenciado.

\section{CONCLUSIÓN}

El modelo colombiano de control disciplinario de los SPEP, además de ser un asunto que ha dado lugar a encendidos debates políticos,

tenciales jueces de segunda instancia en materia de juzgamiento disciplinario sobre SPEP. En virtud del reparto de negocios entre las diferentes secciones de la Sala Plena de lo Contencioso Administrativo, consagrado en el Acuerdo 055 de 2003, la sección segunda de esta Corporación es la encargada de resolver los recursos de apelación que se interponen contra las sentencias de instancia en las que se evalúa la legalidad de los actos administrativos sancionatorios proferidos por la Procuraduría. Por tal motivo, el grueso de la jurisprudencia contenciosa que ha modulado las actuaciones disciplinarias que adelanta la PGN ha sido emitida por esta sección, lo que llevaría a radicar en ella la competencia aludida. En lo que toca con la sección quinta del Consejo de Estado, se tiene que ella conoce las controversias de naturaleza electoral, y, justamente, a este tipo de autoridades judiciales aludía el juez García Sayán como los espacios propicios para proferir sanciones que impliquen el recorte de derechos políticos como el sufragio pasivo. 
deja entrever, cuando menos, una tensión con los estándares internacionales de protección de los derechos políticos. La reconfiguración del juzgamiento disciplinario, mediante la introducción del principio acusatorio, constituye una importante propuesta de reajuste institucional que concilia adecuadamente la necesidad de someter a controles estrictos la gestión de esta clase de funcionarios públicos y la de asegurar el goce efectivo de los derechos políticos. A continuación se registran, a modo de conclusión, los beneficios que encierra esta alternativa.

En primer término, puede afirmarse que la implementación de esta fórmula permitiría superar totalmente la polémica en torno a la convencionalidad de la facultad que actualmente le asiste al MP de sancionar disciplinariamente a IOS SPEP. La razón es simple: convenido que la limitación de los derechos políticos por motivos sancionatorios solo puede presentarse como producto de una decisión emanada de una autoridad jurisdiccional -no necesariamente penal-, con esta propuesta, que sugiere separar las funciones de investigación y juzgamiento, y que le confiere esta última a un juez contencioso administrativo, se superaría el manto de duda que ha generado la compatibilidad del actual diseño institucional colombiano con los estándares interamericanos de protección de derechos políticos. Con ello, se restablecería la seguridad jurídica en materia disciplinaria, que se ha visto diezmada por pronunciamientos judiciales abiertamente contradictorios y que ha terminado por afectar una fluida gestión pública en ciudades como Bogotá, D. C.
Así mismo, se potenciarían los derechos de defensa y contradicción, y se aseguraría la imparcialidad del juzgador. Uno de los argumentos que con frecuencia se aducen para poner en tela de juicio la imparcialidad de los operadores disciplinarios es que la forma de vinculación de los empleados del MP encierra incentivos para que el juzgador no sea indiferente con el resultado de la causa. Según el Decreto 262 de 2000 , los procuradores regionales, distritales, provinciales y delegados son funcionarios de libre nombramiento y remoción. Esta forma de vinculación, aducen algunos, va en desmedro de una adecuada independencia funcional, pues estos funcionarios dependen directamente del procurador general de la Nación. Siendo cargos públicos de una remuneración elevada, pero carentes de estabilidad laboral, es cierto que se abre la puerta a cierto grado de injerencia de la cabeza del mp en las decisiones que estos funcionarios toman. Esta dificultad también se superaría, pues los jueces gozan de las atribuciones de imparcialidad e independencia debido a que, la mayoría de ellos, accede a dicho cargo por concurso de méritos.

Por otro lado, el Estado colombiano reafirmaría su compromiso con la protección de los derechos humanos consignados en instrumentos como la CADH, y se posicionaría como un país pionero en la región en materia de modelos de control disciplinario que aseguren, simultáneamente, el combate frontal contra la corrupción y el respeto por los estándares de protección de derechos políticos. 
Si el rango de aplicación de esta fórmula se ampliara a todos los servidores públicos y particulares que ejercen funciones administrativas, también se superaría el reciente debate en torno a los límites del juez administrativo en el examen de legalidad de los actos sancionatorios.

Con motivo del reciente fallo de la sección segunda del Consejo de Estado, rad. 0263-13, en el que se recalificó la falta disciplinaria y la sanción que la Procuraduría impuso al exalcalde de Medellín, Alonso Salazar, se ha avivado el debate en torno a la interferencia indebida del juez administrativo en las competencias del resorte de la PGN. La postura más ortodoxa indica que el juez administrativo debe limitarse a evaluar la legalidad de los actos sancionatorios, sin que pueda asumir el rol de juzgador disciplinario y, con ello, calificar la conducta investigada a instancias del operador disciplinario. Con la propuesta arriba descrita se superaría esta nueva controversia, pues la naturaleza de los fallos disciplinarios mutaría, pasando de ser actos administrativos controlables por la justicia contenciosa a auténticas decisiones judiciales no susceptibles de esa modalidad de control judicial.

En línea con la anterior consideración, tal y como sucede con los fallos disciplinarios que profiere la Sala Jurisdiccional Disciplinaria del Consejo Superior de la Judicatura sobre los funcionarios de la Rama Judicial, se evitaría después de largos años de debate la anulación judicial de los expedientes disciplinarios sin posibilidad de reconstrucción alguna por haber operado el fenómeno de la prescripción de la acción disciplinaria. De esa manera, se le imprimiría a estas decisiones la seguridad que otorga el fenómeno de la cosa juzgada y se evitaría la impunidad disciplinaria que se genera en tales eventos.

En virtud de esta propuesta también se lograría una verdadera especialización jurisprudencial en los temas disciplinarios. Las reglas judiciales que se irían consolidando gozarían de un mayor grado de conocimiento y otorgarían mayor previsibilidad y seguridad a los servidores públicos.

Por último, aun si este cambio no se extendiera en favor de empleados públicos, trabajadores oficiales y particulares en ejercicio de funciones administrativas, los demás procesos disciplinarios terminarían acicateados por una nutrida jurisprudencia sobre los alcances y las interpretaciones más adecuadas del régimen de faltas, deberes y prohibiciones de nuestros funcionarios públicos. En efecto, si esta propuesta solo cobijara a los SPEP, por conservarse intacta la aplicabilidad de las normas que contienen los deberes, prohibiciones y faltas disciplinarias, las reglas jurisprudenciales que construyera la jurisprudencia "contencioso disciplinaria" deberían ser aplicadas obligatoriamente por el resto de operadores disciplinarios que no ostentaran naturaleza jurisdiccional (oficinas de control interno, personeros, procuradores regionales, etc.).

\section{Referencias}

Asamblea Nacional de la República Bolivariana de Venezuela. (9 de julio de 2002). Ley del Estatuto de la Función Pública. 
Brewer-Carías, A. y Santofimio, J. (2013). Control de convencionalidad y responsabilidad del Estado. Bogotá, D. C.: Universidad Externado de Colombia.

Bulla Romero, J. (2009). Derecho disciplinario. (Tercera ed.). Bogotá, D. C.: Grupo Editorial Ibáñez.

Carvajal, B. (2010). Alcances y limitaciones del debido proceso en el procedimiento administrativo. Revista Digital de Derecho Administrativo, (4), 7-21.

\section{Código Penal Venezolano de 2000.}

Congreso de la República de Colombia. (5 de febrero de 2002). Ley 734 de 2002. Por la cual se expide el Código Disciplinario Único.

Congreso de los Estados Unidos Mexicanos. (22 de diciembre de 1976). Ley Orgánica de la Administración Pública Federal.

Consejo de Estado de Colombia, Sala de lo Contencioso Administrativo, Sección Segunda. Sentencia del 26 de marzo de 2014. Rad. 0263-13 (C. P.: Gustavo Gómez Aranguren).

Consejo de Estado, Sala Plena de lo Contencioso Administrativo. Sentencia de tutela. Rad. 06871 de 2014 (C. P.: Alfonso Vargas Rincón).

Consejo Superior de la Judicatura de Colombia, Sala Jurisdiccional Disciplinaria. Sentencia de tutela. Rad. N 110011102000201308120 01 (M. P.: Pedro Alonso Sanabria Buitrago; marzo de 2014).
Constitución de la Nación Argentina de 1853.

Constitución Política de la República Bolivariana de Venezuela de 2000.

Constitución Política de los Estados Unidos Mexicanos de 1917.

Constituyente. (1991). Constitución Política de Colombia.

Corte Constitucional de Colombia. Sentencia C-280 de 1996 (M. P.: Alejandro Martínez Caballero; junio25 de 1996).

Corte Constitucional de Colombia. Sentencia C-189 de 1998 (M. P.: Alejandro Martínez Caballero; mayo 6 de 1998).

Corte Constitucional de Colombia. Sentencia T-544 de 2004 (M. P.: Jaime Córdoba Triviño; mayo 28 de 2004).

Corte Constitucional de Colombia. Sentencia C-028 de 2006 (M. P.: Humberto Sierra Porto; enero 26 de 2006).

Corte Constitucional de Colombia. Sentencia SU-712 de 2013 (M. P.: Jorge Iván Palacio; octubre 17 de 2013).

Corte Constitucional de Colombia. Sentencia C-500 de 2014 (M. P.: Mauricio González Cuervo; julio 16 de 2014).

Corte Interamericana de Derechos Humanos. Caso López Mendoza vs. Venezuela. Sentencia de 1 de septiembre de 2011. Fondo, Reparaciones y Costas. 
Estados Unidos Mexicanos. Ley de Responsabilidades de los Servidores Públicos. Diario Oficial de la Federación. Diciembre 31 de 1982.

Estados Unidos Mexicanos. Ley de Responsabilidades Administrativas de los Servidores Públicos. Diario Oficial de la Federación. Marzo 13 de 2002.

Ferrajoli, L. (2009). Derecho y razón: teoría del garantismo penal. Madrid: Editorial Trotta.

Gómez Pavajeau, C. (2009). Elementos y propuestas para el control contencioso administrativo de la actividad disciplinaria. Bogotá, D. C.: Instituto Colombiano de Derecho Disciplinario: Ediciones Nueva Jurídica.

Henríquez, G. (2007). La suspensión administrativa de los funcionarios de elección popular. Recuperado el 29 julio de 2014, de ulpiano.org: http://www.ulpiano.org.ve/revistas/ bases/artic/texto/RDUNIMET/11/RDUNIMET_2007_11_216-226.pdf.

Isaza, C. (2009). Teoría general del derecho disciplinario: aspectos históricos, sustanciales y procesales. Bogotá, D. C.: Editorial Temis.

López, D. (2004). Teoría impura del derecho: la transformación de la cultura jurídica latinoamericana. Bogotá, D. C.: Legis.

López, D. (Junio de 2007). El sueño weberiano: claves para una comprensión constitucional de la estructura administrativa del Estado coIombiano. Revista de Derecho Público, (19), 1-42.
Marienhoff, M. S. (1994). Tratado de Derecho Administrativo. Buenos Aires: Abeledo-Perrot.

Pineda de Martínez, R. (2002). Manual práctico: Ley 734 comentada y concordada. Bogotá, D. C.: Ediciones Librería del Profesional.

Presidencia de la República de Colombia. (22 de febrero de 2000). Decreto 262 de 2000. Por el cual se modifican la estructura y la organización de la Procuraduría General de la Nación y del Instituto de Estudios del Ministerio Público; el régimen de competencias interno de la Procuraduría General; se dictan normas para su funcionamiento; se modifica el régimen de carrera de la Procuraduría General de la Nación, el de inhabilidades e incompatibilidades de sus servidores y se regulan las diversas situaciones administrativas a las que se encuentren sujetos.

Quinche, M. (2009). Los estándares de la Corte Interamericana y la Ley de Justicia y Paz. Bogotá, D. C.: Universidad del Rosario.

Ramírez Rojas, G. (2008). Dogmática del Derecho Disciplinario en preguntas y respuestas. Bogotá: Procuraduría General de la Nación, Instituto de Estudios del Ministerio Público.

República Argentina. Decreto 102 de 1999. Oficina Anticorrupción.

República Argentina. Decreto 1421 de 2002. Ley Marco Regulatorio del Empleo Público.

República Argentina. Decreto 41 de 1999. Código de Ética de la Función Pública. 
República Argentina. Decreto 467 de 1999. Reglamento de Investigaciones Administrativas.

República Argentina. Ley 24667 de 1996. Ley de Pequeñas y Medianas Empresas.

República Argentina. Ley 24759 de 1997. Aprobatoria de la Convención Interamericana contra la Corrupción.

República Argentina. Ley 25164 de 1999. Ley Marco de Regulación de Empleo Público Nacional.
República Argentina. Ley 25188 de 1999. Ley de ética de la Función Pública.

República Bolivariana de Venezuela. (Julio 11 de 2002). Ley del Estatuto de la Función Pública. Gaceta Oficial n. ${ }^{\circ} 37522$.

Zweigert, K. y Köts, H. (2002). Introducción al derecho comparado. México D. F.: Oxford University Press. Harla México. 